\title{
Sophie Chevalier, Jean-Marie Privat (dir.), Norbert Elias. Vers une science de l'homme
}

Paris, CNRS Éditions, coll. « Biblis », 2013, 426 p.

\section{Nadia Garnoussi}

\section{(2) OpenEdition}

\section{Journals}

Édition électronique

URL : http://journals.openedition.org/assr/26356

DOI : 10.4000 /assr.26356

ISSN : $1777-5825$

Éditeur

Éditions de l'EHESS

Édition imprimée

Date de publication : 31 décembre 2014

Pagination : 162

ISBN : 978-2-7132-2467-6

ISSN : 0335-5985

\section{Référence électronique}

Nadia Garnoussi, «Sophie Chevalier, Jean-Marie Privat (dir.), Norbert Elias. Vers une science de I'homme », Archives de sciences sociales des religions [En ligne], 168 | 2014, mis en ligne le 09 avril 2015, consulté le 22 septembre 2020. URL : http://journals.openedition.org/assr/26356 ; DOI : https:// doi.org/10.4000/assr.26356

Ce document a été généré automatiquement le 22 septembre 2020

(C) Archives de sciences sociales des religions 


\section{Sophie Chevalier, Jean-Marie Privat (dir.), Norbert Elias. Vers une science de l'homme}

Paris, CNRS Éditions, coll. « Biblis », 2013, 426 p.

Nadia Garnoussi

\section{RÉFÉRENCE}

Sophie Chevalier, Jean-Marie Privat (dir.), Norbert Elias. Vers une science de l'homme, Paris, CNRS Éditions, coll. « Biblis », 2013, 426 p. 
1 Si l'œuvre de Norbert Elias est devenue un classique de la sociologie, en revanche elle aura été peu exploitée par les anthropologues - et cela constitue l'une des raisons d'être de cet ouvrage collectif paru en 2004 et réédité en 2013. Deux raisons principales à cette inégale réception sont précisément explicitées en introduction. Tout d'abord, les objets et la perspective de Norbert Elias concernent très directement les sociétés occidentales, ce qui les éloigne des terrains privilégiés de l'anthropologie; et à ceci s'ajoute que ses analyses ont été suspectées de véhiculer une forme de pensée évolutionniste, justifiant ainsi doublement leur mise à la marge du champ de recherches de l'anthropologie. $\mathrm{Au}$ centre de cette marginalisation la thèse fameuse $d u$ «processus de civilisation » qui a pu être interprétée

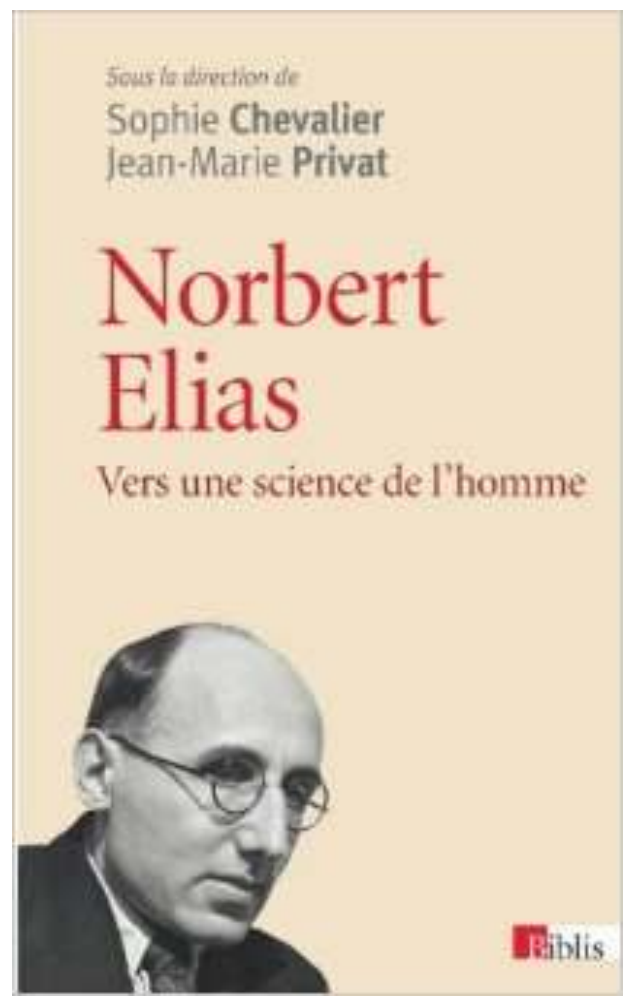
comme relevant d'un ethnocentrisme, posant le problème de son application aux sociétés non occidentales, et qui a par ailleurs questionné son adéquation aux faits historiques.

Précisément, c'est en proposant de déplacer le regard longtemps focalisé par les anthropologues sur le processus de civilisation et de l'élargir aux autres travaux de Norbert Elias, en particulier ses travaux puisant dans une approche historique et comparative, que cet ouvrage entend montrer la richesse et la pertinence de ses apports à l'anthropologie. Les auteurs rappellent en introduction qu'Elias reprochait même à cette dernière de ne pas suffisamment considérer les dynamiques historiques qui façonnent les structures sociales. Quant à l'approche comparative que prescrit Elias, elle pourrait en particulier permettre de répondre à un «objectif fondamental " de l'anthropologie, qui consiste à rendre compte des spécificités culturelles entre les sociétés et doit pouvoir ainsi en expliciter les variations.

Revendiquant son caractère "polyphonique », l'ouvrage rassemble des contributions de chercheurs de renom issus de plusieurs disciplines - l'anthropologie, la sociologie, l'histoire, les sciences de l'éducation, la littérature - qui permettent de revisiter dans des contextes pluriels les grandes conceptualisations éliasiennes : celle de "processus de civilisation", pensée à nouveaux frais, mais aussi de "configuration », de " sociogenèse » et de " psychogenèse ", $d$ ' « autocontrainte ", conceptualisations dont la richesse réside dans le souci de penser ensemble les transformations de la structure sociale, des institutions et des économies psychiques.

La diversité de ces contributions est organisée en six parties, recouvrant vingt-trois chapitres. La première réunit les contributions discutant de la place des travaux de N. Elias dans le champ de l'anthropologie générale. La seconde permet de revenir précisément sur le processus de civilisation, notamment via des analyses sur la société de cour. La troisième s'attache à l'anthropologie du politique. La quatrième partie 
investigue les différents éclairages que fournit Elias sur l'organisation des sociétés contemporaines et de ses mœurs, au travers des thèmes centraux de la mort, de la politesse, de la socialisation scolaire et de la construction de la sphère privée dans la société des individus. La cinquième partie propose d'explorer de «nouveaux champs culturels » liés à la littérature et à l'art. Les deux derniers chapitres réunis dans la sixième partie comprennent une réponse aux interprétations critiques de D. Gordon de l'œuvre d'Elias et une discussion finale sur la «contre-épreuve» que le refus contemporain des normativités répressives ou contraignantes impose au processus de civilisation.

5 Sans rendre compte ici de la richesse des analyses et des discussions contenues dans cet ouvrage, soulignons qu'il réussit le pari, en mettant en regard une diversité d'approches théoriques et empiriques, de dégager la portée pluridisciplinaire des analyses éliasiennes. Celles-ci sont donc bien constitutives en ce sens d'une véritable "science de l'homme ", pour reprendre le titre de l'ouvrage, qui ne saurait être réduit à un seul domaine d'expertise, mais éclaire nombre des aspects de nos mondes contemporains et plus anciens. 